La crisis de los principios espirituales y sociales del proceso penal reformado.

Felix Herzog

páginas $375-386$

\title{
LA CRISIS DE LOS PRINCIPIOS ESPIRITUALES Y SOCIALES DEL PROCESO PENAL REFORMADO*
}

Felix Herzog**

Las líneas centrales de la actual discusión político-criminal son la ampliación de la autorización de investigación penal de la policía, la agilización del proceso penal a través de la disminución de las formalidades procesales y de los derechos de defensa, el adelantamiento de la punibilidad con el propósito de un efectivo control social penal, y el endurecimiento de las penas.

En la discusión populista sobre el "estado catastrófico" de nuestra justicia penal se acusa al Derecho Procesal de estar anticuado y de ser ineficaz para la misión del actual sistema de justicia criminal: Es una situación insostenible que el Derecho Penal y Procesal Penal se enfrenten a las formas de aparición de la criminalidad en el umbral del siglo XXI todavía con una autocompresión, unos principios y unos instrumentos inventados en la ideología burguesa del Estado liberal de finales del siglo XIX.

El descubrimiento de la víctima por parte de la Política Criminal de los últimos diez años añade una nueva carga emocional a esta acusación. Las especiales consideraciones del "viejo" Derecho Procesal Penal para respetar los derechos del inculpado son a menudo presentadas -en una deformación demagógica- como un olvido ante los sufrimientos de las víctimas.

\footnotetext{
* Título original "Die Krise der geistigen und sozialen Grundlagen des reformierten Strafprozesses", publicado en F. Herzog (Coord.), Quo vadis, Strafprozeß?, Nomos Verlagsgesellschaft, Baden-Baden, 1998, pp. 21 a 32. Traducción de la conferencia a cargo del Dr. Raúl Núñez Ojeda, Profesor de Derecho Procesal en la Universidad de Chile y profesor invitado en la Universidad Pompeu Fabra (España). Correo electrónico: raununez@derecho.uchile.cl; raul.nunez@ucv.cl

** Catedrático de Derecho Penal, Procesal Penal y Filosofía del Derecho Universidad Bremen (Alemania)
} 
Con las expresiones "criminalidad organizada" y "criminalidad callejera" se ha hablado a favor de una acción de la policía y la justicia que debe caracterizarse por una orientación hacia la eficacia y una pérdida del miedo a actuar con dureza. La "zero tolerance" de la policía y los "procesos abreviados" de la justicia son dos caras de la misma moneda que a los procesalistas penales decididos les gustaría ponerse en la solapa.

"Criminalidad: uno de cada dos berlineses vive con miedo", era el titular del periódico berlinés "Boulevardzeitung" en otoño de 1997 como inicio de una serie de reportajes. Y todos tenemos el presentimiento de que la lucha contra la criminalidad y los supuestos déficits del sistema de justicia criminal serán temas centrales en la campaña electoral de 1998. Los resultados de las encuestas muestran un continuo aumento de la percepción de la criminalidad y, sobre todo, de la criminalidad violenta como problema social central de nuestra sociedad. Mientras tanto, la criminalidad se encuentra en la segunda posición en el ranquing de los miedos sociales detrás del desempleo y muy por delante de las pensiones de jubilación, de la situación del sistema de salud o de las amenazas al medio ambiente. Existe el peligro de que surja una política de "law and order" en el debate de las ideas que se forjan en las tertulias, y que se perciban sólo como una carga las consideraciones del Estado de Derecho liberal en la lucha contra la criminalidad.

Lo que conviene preguntarse es cómo debe tratarse esta situación político-criminal, cuando se quiere defender el Derecho Penal y el Derecho Procesal Penal frente a una "intervención de una política populista" (Peter-Alexis Albrecht), cuando se quiere insistir en que el Derecho Procesal Penal debe ser entendido como un "Derecho limitador de la lucha contra el crimen" (Naucke).

La revisión de muchas publicaciones de los últimos años, y también por cierto de mis propios estudios, para la preparación de esta conferencia me ha dejado muy descontento. Casi no existe un diálogo fructífero entre la ciencia y la política. Para exponerlo en una imagen: los perros ladran, la caravana avanza, o dicho con mayor contundencia, uno se siente como predicando en el desierto. Y lo que se predica se convierte progresivamente en confesión, uno apunta su reflexión o da explicaciones políticas -¿pero dirigidas a quién?-. Baste con un par de citas ilustrativas:

"Es necesario....un retorno de la correcta teoría en la praxis";

"Es necesario repensar el Derecho Penal clásico del Estado de Derecho liberal" .

Cita de Christine Pott, "Die Aushöhlung des Legalitätsprinzips", en Vom unmöglichen Zustand des Strafrechts, Institut für Kriminalwissenschaften Frankfurt, Frankfurt, 1995, pp. 79 y ss. [Existe una traducción al español bajo el título: "El fenómeno de pérdida de contenido del principio de legalidad y su manifestación en las relaciones 
La crisis de los principios espirituales y sociales del proceso penal reformado.

O para citarme a mí mismo el año 1991:

"Precisamente a la vista de las experiencias que tuvieron los ciudadanos de los nuevos "Länder" en los últimos 45 años con la policía y los organismos de seguridad, así como con la justicia de la República Democrática Alemana, sería conveniente para la Alemania reunificada reaccionar con la serenidad propia de un Estado de Derecho ante las nuevas formas de criminalidad y ante el aumento de la carga criminal. Toda sociedad libre debe vivir con un cierto nivel de criminalidad, si se declara partidaria de un Derecho Penal propio de un Estado de Derecho y se considera la omnipresencia de la policía en la vida social como una desventaja".2

Si no quiere abandonarse el ámbito de la política criminal a la opinión pública, hay que salir de estas reflexiones y revisiones, teniendo que tomar en serio la preocupación y problemas de la gente, y desarrollar nuevas perspectivas para el sistema de justicia criminal. Salir de esta reflexión no significa poner ad acta el Estado de Derecho liberal-burgués. Hay que preguntarse desde la perspectiva de un análisis crítico, qué potencial utópico se encuentra en los ideales del Estado de Derecho liberal-burgués del siglo XIX, pero también, qué se muestra como ideología mirando retrospectivamente.

\section{II}

La ilustración y el liberalismo político prepararon el tránsito del proceso inquisitivo del Derecho común al Derecho Procesal Penal reformado.

El modelo de proceso penal que defiende la libertad del acusado y le reconoce la condición de sujeto en el proceso es consecuencia de la idea del contrato social. Un orden estatal sólo es eficiente, y legítimo al mismo tiempo, si reconoce las libertades de las personas que se agrupan a su amparo, que frena su propio poder y que se vincula a las Leyes.

Estos postulados no eran compatibles con un proceso que trataba al acusado como un mero objeto de investigación, donde el inquisidor poseía los mayores poderes, celebrado a

entre el delito de encubrimiento por funcionario ( $\$ 258 \mathrm{a} \mathrm{StGB})$ y el sobreseimiento ( $\$ 153 \mathrm{StPO})$ ”, trad. E. Íñigo y G. Benlloch, en La insostenible situación del Derecho Penal (Área de Derecho Penal de la Universidad Pompeu Fabra), Comares, Granada, 1999, pp. 79 y ss. (N. del T.)]. No se trata de denunciar aquí ese tipo semejante de aproximación al fenómeno de la disolución de los ideales liberales burgueses del proceso penal, sino que se quiere marcar su distancia de la realidad. Una distancia así, como distanciamiento, puede llevar a una posición político-criminal estilizada, la cual pierde totalmente de vista la política criminal real.

2 Yo intentaba postular en noviembre de 1991 el retroceso de los métodos ocultos de investigación de la policía en una conferencia en la Academia de Policía de Münster-Hiltrup con el título "Muß die Polizei mehr wissen dürfen oder soll sie nicht so neugierig sein?’.Ya en aquel entonces la posición de casi todos los participantes en la discusión fue la de que la policía en la lucha contra la criminalidad organizada no puede saber suficiente. Desde entonces esto se ha establecido como una guía por sobre de los partidos en la política criminal. 
puerta cerrada, substanciado por escrito, que no conocía la participación de los legos y cuyas sentencias podían ser modificadas por el poder del señor feudal. Esta forma procesal se mostraba además en gran medida incompatible con los objetivos de la burguesía floreciente. El Estado policial, tal como se desarrolló a consecuencia del absolutismo y como reacción a la Revolución Francesa, entremezclando el proceso inquisitorio con su gran afán de persecución y lo convierte en un instrumento para disciplinar a las mentes libres. ${ }^{3}$

Las persecuciones de los demagogos de la época de la "reacción” y los procesos de prensa de principios del siglo XIX fueron quienes llevaron a que los liberales burgueses atribuyeran una gran importancia a la reforma del proceso penal para la emancipación. La eliminación del proceso inquisitorio debe entenderse en este contexto como una exigencia política. Ello significa, al mismo tiempo, que todos los principios que deberían definir en adelante el proceso penal reformado, han de ser vistos en un contexto político. Formas de protección, publicidad, oralidad, principio acusatorio, derecho a ser oído, eliminación de la justicia de gabinete y participación de los legos, responden a los intereses de la burguesía liberal en su lucha por las libertades de los ciudadanos. ${ }^{4}$

Por el contrario, la hipótesis de que la mayoría de los representantes de la burguesía habían aspirado a una reforma de la administración de justicia penal en favor del "pueblo" parece dudosa según la bibliografía y los estudios sociológico-históricos ${ }^{5}$. "Concordia, Derecho y libertad" fueron los lemas de la revolución de 1848/49, y no "Libertad, igualdad y fraternidad" como en la revolución francesa de 1789.

El Paulskirchenparlament estaba compuesto por un $10 \%$ de profesores, cerca de un $35 \%$ de funcionarios, cerca de un $28 \%$ de juristas de libre ejercicio de la profesión, y cerca de un $15 \%$ de miembros de la aristocracia, cuyo factor de consenso se basaba en el liberalismo nacional y no en el liberalismo radical. En los debates sobre la justicia penal, la criminalidad de las clases sociales bajas no desempeña un papel demasiado importante, sino que lo que interesa es impedir una criminalización política de los miembros de la burguesía floreciente.

Respecto a la participación de los legos en la administración de la justicia penal, se discute detalladamente sobre la conveniencia de excluir del censo a las personas que carecen de conocimientos por factores de orden económico o educacional. Así como el parlamento se entiende como la expresión de las libertades conseguidas recientemente en el campo político,

Cfr. Schmidt, E. Einführung in die Geschichte der deutschen Strafrechtspflege, Göttingen, 1983, p. 201.

Cfr. al respecto la exposición de Schmidt, E. cit. Nota 3, pp. 287 y ss.

Muchos de los materiales para el siguiente análisis se encuentran en Landau, P. "Schwurgerichte und Schöffengerichte in Deutschland im 19. Jahrhundert bis 1870", en Padoa, A. (Dir.), The Trial Jury in England, France, Germany 1700-1900, Berlin, 1987, pp. 241 y ss. (254 y ss.). 
La crisis de los principios espirituales y sociales del proceso penal reformado.

los tribunales del jurado deben asegurar la representación de la burguesía en la administración de justicia.

En el proceso penal burgués del siglo XIX este trasfondo político se plasma enseguida en una disgregación entre los ideales y la praxis. Cuando la Ordenanza Procesal Penal del Reich $(R S t P O)$ tomó forma en los años 70 del siglo XIX, según la estadística fiscal prusiana, más o menos el 70\% de la población eran trabajadores asalariados de las industrias o agricultores, y sólo un 5\% pertenecía a la burguesía intelectual.

Ya en la década anterior era evidente, que la justicia penal era fiel a la frase de Schiller: "Es deshonroso, vaciar una cartera -y es vergonzoso, defraudar un millón-pero robar una sóla corona es tan grave que no hay palabras. La vergüenza disminuye cuanto mayor es el pecado". Mientras contra un delito tan burgués como la bancarrota se procede respetando todas las formas y sus consecuencias no son graves, el hurto, como ataque a la propiedad de los burgueses, se ventila en procesos sumarios y se castiga con penas severas ${ }^{6}$. Aunque estas palabras contienen aún hoy una carga emocional y pueden provocar mucha confusión, puede afirmarse que el proceso penal burgués del siglo XIX muestra signos evidentes de ser una justicia de clases.

Sin embargo no quiero desarrollar más este aspecto, pues sólo debe servir para una primera relativización del Derecho Penal liberal como punto de referencia para una crítica actual a la evolución del Derecho Penal.

La segunda relativización debe acometerse por el camino de la crítica ideológica. En la dogmática procesal penal de la misma época y en la literatura histórica posterior sobre la reforma del proceso penal se efectúa a menudo la analogía entre el parlamentarismo y el proceso penal reformado ${ }^{7}$, cuya asociación ya se ha mencionado antes.

Por ejemplo, en su "Manual para la defensa en el proceso criminal" (Anleitung zur Verteidigungskunst im Kriminalprozeß 1814) el procesalista y político Karl Joseph Anton Mittermaier enfatiza la importancia del enfrentamiento entre la acusación y la defensa en el proceso penal para la obtención de la verdad. Ello recuerda la idea del equilibrio de fuerzas opuestas, de cuyo equilibrio surge lo justo en sí mismo ${ }^{8}$. Junto a la teoría de la separación de poderes en la tradición de Montesquieu, esta idea también se recoge en la teoría del

Cfr. Landau, cit. Nota 5, pp. 287 y ss.

Ver la exposición concentrada en Schmidt, E. cit. Nota 3, p. 290.

Léase sobre este aspecto el resumen de la obra sobre el proceso penal de Mittermair en Schmidt, E. cit. Nota 3 , p. 265 . 
parlamentarismo, por ejemplo, en Bentham. "Goverment by discussion" para Bentham significa que "en el parlamento se enfrentan las ideas y en el choque de las ideas saltan chispas que llevan a la evidencia".

Esta idea sólo es "verdadera” si el parlamento es realmente un lugar de decisión a través de la discusión ${ }^{9}$. Para que ello sea así, son necesarios un interés nacional como denominador común mínimo de las convicciones y una armonía social preexistente. Sin embargo, este modelo se quiebra desde el momento en que los partidos en el Parlamento ya no se enfrentan entre sí como en un club burgués de debate, sino como grupos sociales de poder que se acusan mutuamente de desatender los intereses nacionales o de traicionarlos. Las decisiones políticas importantes ya no son el resultado del equilibrio de las opiniones en la discusión pública, sino que se basan en el calculo de intereses y posibilidades de poder; y las coaliciones y compromisos se basan también en este presupuesto fáctico.

En consecuencia, puede formularse la tesis de que muchas de las formas de agotamiento del proceso penal se basan en el fenómeno de la pérdida del interés común en el proceso y en una armonía preexistente. Más adelante volveré sobre esta cuestión.

A la luz de la crítica al abismo existente entre la ideología y la praxis del proceso penal burgués en el contexto de la emancipación burguesa del siglo XIX, conviene analizar brevemente por qué puede tener sentido vincular esta crítica a la actual evolución del proceso penal con las raíces del Estado de Derecho.

Sin duda, la teoría del proceso penal del Estado de Derecho en el siglo XIX es una gran obra y una gran idea. La Ordenanza Procesal Penal del Reich aparece en la época del florecimiento de la burguesía, que se caracteriza por unas condiciones políticas bastante equilibradas y establecidas, por una saturación en el campo económico, por una industrialización creciente, por una unidad nacional y por una voluntad de progreso basada en una imagen del hombre fundamentalmente optimista. El sistema de la Ordenanza Procesal Penal del Reich es un gran logro de la técnica legislativa, su lenguaje tiende a la precisión y a la validez general. Una composición elocuente en situación de intereses divergentes no se encontrará en la Ordenanza Procesal Penal del Reich; aspira con razón a la "armonía entre seguridad y libertad" (Mittermaier).

En este sentido la burguesa Ordenanza Procesal Penal del siglo XIX es una ley que tiene

9 Con toda la reserva frente a la posición política que se deriva, esto ha sido analizado con gran transparencia en Schmitt, C. Die geistesgeschichtlichen Lage des heutigen Parlamentarismus, Berlin, 1991, pp. 8 y ss. (Bentham es citado en la pág. 12) [Existe una traducción al español como: Sobre el parlamentarismo, trad. T. Nelsson y R. Grueso, Tecnos, Madrid, 1990 (N. del T.)]. 
La crisis de los principios espirituales y sociales del proceso penal reformado.

un gran respeto por los derechos de los ciudadanos. Sin embargo, a la vista de la cada vez más urgente cuestión social en el momento de su codificación puede aplicarse a la Ordenanza Procesal Penal el juicio desapasionado de Hermann Heller, quien entiende que las codificaciones fueron "grandes ocultaciones de una situación en contra" de la sociedad. ${ }^{10}$

A tal efecto, baste con recordar las famosas palabras de Anatole France de que la Ley con su majestuosa igualdad prohíbe por igual, tanto a ricos como a pobres, dormir bajo los puentes, mendigar en la calle y robar el pan. Así es como garantizaba la Ordenanza Procesal Penal a cualquier persona un proceso de acuerdo con el Estado de Derecho, con la garantía de todas las formas de defensa, siempre que contara con la competencia social, las capacidades comunicativas y los medios financieros para reclamar su derecho, o que cayera en manos de un Tribunal sensible a los problemas sociales, o encontrara para su caso un abogado comprometido socialmente.

Abogados criminalistas como Max Alsberg fueron quienes repetidamente se hicieron eco en su trabajo de las contradicciones entre lo que, de acuerdo con su concepto, debería ser el proceso penal liberal y lo que se aplicaba en la práctica. Fueron ellos también quienes desarrollaron estrategias de defensa en las que se exigía la aplicación de las garantías jurídicas. El marco pragmático y el contenido utópico del conflicto con los ideales del Estado de Derecho liberal en el proceso penal pueden ser los siguientes: poner de manifiesto la contradicción entre fe y realidad como contradicción práctica y hacer hincapié en algo utópico que hay que realizar de manera concreto-práctica.

Para las reflexiones programáticas sobre el futuro del proceso penal, en cambio, no sirve reflexionar sobre la edad de oro del proceso penal liberal en un Estado de Derecho. La regresión ideológica lleva simplemente a una transfiguración romántica y se llega al lema "todo lo que fue, es verdad", aunque -como yo quería mostrarles- no haya sido así.

Quién a la pregunta “¿quo vadis, proceso penal?” responde “volver al bueno, viejo y razonable proceso penal liberal” está indicando un punto en el tiempo que sólo puede buscarse en vano. ${ }^{11}$

Heller, H. Staatslehre, Leiden, 1934, p. 112 [Existe una traducción al español como: Teoría del Estado, trad. L. Tobio, Fondo de Cultura Económica, Ciudad de México, 1942 (N.del T.)].

11 He tomado el título de la crítica al romanticismo del núcleo del Derecho Penal (Kernstrafrechts) de Lüderssen, K. "Zurück zum guten alten liberalen anständigen Kernstrafrecht?", en Böllinger/Lautmann, Vom Guten, das noch stets das Böse schafft, Frankfurt, 1993, pp. 268 y ss. 


\section{III}

Las consecuencias de los cambios de las condiciones sociales básicas para la comprensión del Derecho Penal y el Derecho Procesal Penal han sido descritas de forma clarividente por Eberhard Schmidt en su "Introducción a la historia de la justicia penal alemana" (Einführung in die Geschichte der deutschen Strafrechtspflege 1947) y sirven también para nuestra actual época de transición. Permítanme ofrecer una cita más larga:

"Uno de los aspectos más trágicos en la historia del Derecho del pueblo alemán es que, justo en el momento en el que la constitución de un Estado de Derecho liberal y el reconocimiento de los derechos tendrían que haber adquirido práctica, el modelo de hombre burgués deja de ser determinante para la estructura social del pueblo alemán. El poderoso incremento de la técnica, el desarrollo económico posterior a la unificación del pueblo alemán, fueron la causa de la industrialización y del crecimiento de las grandes ciudades, que, por un lado, proporcionaron inesperadas posibilidades en el ámbito cultural, pero, por otro lado, en sus campamentos de miseria producían un germen terrible para la tensión social y política a cuya problemática inescrutable la humanidad empezaba a enfrentarse cada vez más desconcertada. De este modo la cuarta clase social se convierte en un factor político de importancia creciente que se enfrenta a todo lo burgués. El peligro de estos contrastes sociales no fue comprendido por aquella parte de la burguesía que, como portadora del avance económico, participaba de manera importante en la riqueza y en el poder económico. Precisamente en este sector de la burguesía se produjeron movimientos críticos de carácter intelectual y ético. La idea liberal en el sentido de Kant con las ásperas exigencias de comportamiento y acción del imperativo categórico y su obligación humana frente a todo lo humano se perdió para este sector. Se quería ser "liberal", en el sentido de una libertad absoluta de todos los compromisos y obligaciones para emplear todas las fuerzas en una ambición desconsiderada de poder, honor y gloria. El idealismo ético, del que partió el impulso y la influencia intelectual del liberalismo de principios del siglo XIX, cedió en gran medida su lugar a un materialismo extremo, ciego ante la gran tarea social". ${ }^{12}$

Estas frases muestran una descripción de la indiferencia neoliberal actual frente a la decadencia de la solidaridad social y la erosión de las normas sociales. Esta creciente indiferencia va unida de manera extraña a un análisis del sistema de justicia criminal con todas las posibles circunstancias económicas, sociales y políticas. Cada vez más se carga al Derecho Penal con severas exigencias de solución de complejos problemas sociales:

- Por ejemplo, de la decadencia de los estándares mínimos éticos en la economía y en la administración (palabra clave: corrupción).

12 Schmidt, E. cit. nota 3, p. 304. 
La crisis de los principios espirituales y sociales del proceso penal reformado.

- De la contaminación de los mercados financieros globales con beneficios criminales (palabra clave: lavado de dinero).

- Del desplazamiento inhumano de residuos tóxicos a países en desarrollo (palabra clave: criminalidad organizada medioambiental).

- De los signos de degeneración de una comercialización desenfrenada de la sexualidad (palabra clave: pornografía infantil).

Desde luego es digno de ser destacado que los fiscales y los jueces se enfrenten a tales problemas y vean en su tarea -como hace poco ha expresado oportunamente en un congreso el juez de Frankfurt Thomas-Michael Seibert-, en reducir la complejidad a la responsabilidad individual y en dar un nombre al mal. Sin embargo, debe criticarse que la administración de justicia deba encargarse de contrarrestar la progresiva desaparición de las normas sociales y la desorientación ética y moral, mientras los políticos se limitan a lamentarse de la pérdida de valores en sus discursos dominicales y no dan ningún impulso real para la solución de los problemas sociales.

Por ejemplo, si uno pasa revista a las publicaciones políticas del verano de 1997 sobre la crisis presupuestaria, en el mercado del trabajo, en el sistema de salud o en las pensiones, se evidencia de dónde proviene la enorme desconfianza del hombre en la competencia de la política para resolver problemas, es decir, la crisis de confianza en los portadores de decisiones políticas. Ante este trasfondo, la delegación de los graves problemas sociales en la justicia penal parece a menudo una especie de "golpe de liberación" con el que la política quiere aparentar decisión y capacidad de actuación.

Además es evidente que -como Eberhard Kempf ha expuesto en su conferencia de Paulskirchen ante el $41^{\circ}$ Jornadas de abogados alemanes ( $41^{\circ}$ Deutschen Anwaltstag) en mayo de 1997- la asignación de tareas de este género a la justicia penal lleva por fuerza, "a que el Derecho Procesal Penal consiga cada vez menos cumplir correctamente su misión de aclarar la responsabilidad jurídica de manera legal" ${ }^{13}$. Así, por ejemplo, ante la errática política de Alemania y los Estado Unidos de América para el oriente próximo, es evidente que por fuerza hay que acabar en un "proceso monstruoso" cuando un tribunal tiene que aclarar si en las relaciones comerciales de una empresa alemana con Irak durante los años ochenta se realiza algún tipo penal de la Ley de Economía Exterior, y ello aun cuando existe acuerdo internacional, tras la invasión de Kuwait en que en Irak existe un régimen criminal.

El Derecho Penal y la justicia penal no deben confundirse con unos portadores de esperanza para la solución de los complejos problemas sociales y políticos. El procedimiento penal fracasa

13 Kempf, "Die Funktion von Strafrecht und Strafverteidigung in einer modernen Gesellschaft", NJW, 1997, pp. 1729 y ss. (1731) 
por fuerza en la superación de estos problemas, pues está pensado para tratar conflictos entre hombres y no para individualizar responsabilidades para las grandes perturbaciones sociales y políticas.

Para poner fin a mi conferencia voy a ocuparme de realizar algunas reflexiones prácticas sobre la pregunta “¿Quo vadis, proceso penal?”. Hasta ahora he intentado mostrarles que no había camino de vuelta hacia el bueno, viejo y razonable proceso penal liberal, y que las indicaciones de la política criminal moderna llevan a un callejón sin salida.

Sin embargo, también estoy de acuerdo con mi maestro Winfried Hassemer en que "especialmente en tiempos como los nuestros, caracterizados por la erosión de las normas y el cambio de valores, debe haber ámbitos en los que se pueda discutir sobre la validez de las normas generales de forma clara, responsable y fructífera. Uno de estos ámbitos es el sistema penal". ${ }^{14}$

¿Cómo debe actuarse en este ámbito?, citando una hermosa formulación del profesor de Derecho Penal de Munich Klaus Volk, no debe procederse como en una "bolsa en la que se negocia libremente y sin reglas respecto a las cotizaciones de la justicia". ${ }^{15}$

Los pactos y las negociaciones en el proceso penal son las consecuencias de la atribución de tareas globales al sistema de justicia penal que antes he expuesto, de un Derecho Penal construido de forma cada vez más omnipresente, de una tendencia a anticipar las barreras de lo punible y de tipos penales totalmente indeterminados, en definitiva, de una política de reacción a la inseguridad social mediante una asistencia vital (Daseinsvorsorge) penal. En estas condiciones -me refiero de nuevo a la analogía de la crisis del parlamentarismo con la crisis del proceso penal- no se puede esperar que la verdad surja de la contradicción entre la acusación y la defensa, sino que en el proceso penal influyen cuestiones de poder social y político que sólo pueden resolverse mediante el compromiso. Ya no sirve el principio de legalidad procesal, sino que se negocia a partir de una distribución políticamente inteligente de los recursos de la pretensión punitiva estatal.

Estas peleas por el reparto surgen en la práctica de querellas de la fiscalía que ocupan más de cien páginas, bien intencionadas, pero perdidas terriblemente en la complejidad, con una enorme cantidad de testigos y peritos, acompañados por centenares de diligencias instructoras.

$14 \quad$ Hassemer, "Warum und zu welchem Ende strafen wir?”, ZRP, 1997, pp. 316 y ss. (319) [Existe una traducción al español de este trabajo por $\mathrm{M}^{\mathrm{a}}$. del Mar Díaz Pita, bajo el título “¿Por qué y con qué fin se aplican las penas? (Sentido y fin de la sanción penal), en Revista de Derecho Penal y Criminología, núm. 3, 1999, págs. 317 a 331 (N. del T.)].

$15 \quad$ Volk, "Entkriminalisierung durch Strafwürdigkeitskriterien jenseits des Deliktsaufbaus", ZStW, núm. 97, 1985, pp. 897 y ss. (911). 
La crisis de los principios espirituales y sociales del proceso penal reformado.

Ni el más avezado Magistrado consigue una apropiada, objetiva y económica estructuración del proceso. Cuanto mayor es el número de acusados y medios probatorios, más se atisba el potencial de defensa, lo que lleva a efectos cumulativos en la práctica de los derechos procesales. De acuerdo con la reforma legal para simplificar el proceso, ante el Tribunal del Land (Landgericht) en primera instancia sólo se tratan acusaciones que pueden llevar a una pena considerable y en este caso sólo queda el recurso de casación. Por ello cada vez más las partes en el proceso emplean un enorme gasto y despliegue de medios ${ }^{16}$. Algún día el carro quedará detenido en el barro.

El que una equivocada política criminal tenga parte de responsabilidad en este tipo de procedimientos intrincados es algo que se oculta al público.

Como motivos que surten efecto entre el público, se mencionan la ausencia de límites del vigente Derecho de prueba, la abundancia de derechos de la defensa y su abuso por parte de los defensores. Aquí se hace necesario una aclaración sobre la realidad cotidiana del proceso penal.

La realidad jurídica en procedimientos ante el Juzgado Municipal (Amtsgericht), donde se discute la parte principal de las acusaciones, no es un procedimiento extremadamente largo, sino un procedimiento en cadena. Si existe una confesión creíble de los acusados, el Tribunal suele renunciar a una amplia práctica de la prueba y a menudo se renuncia incluso a la citación de testigos. La máxima de la libre valoración de la prueba se practica de tal modo que el Tribunal funda su convicción en la confesión. Todo ello dura entre 20 y 30 minutos, porque en muy pocas ocasiones se involucra un defensor motivado en este tipo de procedimientos, ya que las proposiciones de prueba, que hacen difícil la vida a los jueces, se inadmiten.

Por tanto, debe de nuevo preguntarse: ¿Cómo debe debatirse en el proceso penal sobre la vigencia de las normas generales, sobre la justicia y la injusticia?.

Con la fulminante razón práctica que le caracteriza, Claus Roxin ha introducido las siguientes ideas en la discusión ${ }^{17}$ :

Hay dos tipos diferentes de inculpados y, por tanto, dos clases también de defensas: unos buscan un transcurso y final favorables del procedimiento a través de la confrontación; los otros, son desde un principio total o esencialmente confesos, dispuestos a aceptar la sanción y quieren salir bien librados gracias a la cooperación.

16 Cft. esto con lo reciente de Ter Veen, “Zu den Gründen (über-)lager Verfahrensdauer in Strafsachen”, StV, 1997, pp. 374 y ss.

17 Roxin, "Über die Reform des deutschen Strafprozeßrechts", en Wie würden Sie entscheiden?. Festschrift für Gerd Jauch, München, 1990, pp. 183 y ss. (190 y ss.). 
Por este motivo el ordenamiento jurídico debería ofrecer para el proceso penal respectivamente dos modelos diferentes: un procedimiento de cooperación y uno de confrontación.

En el procedimiento de confrontación el inculpado quiere luchar en la mayoría de los casos por una sentencia absolutoria. En estos casos los rasgos esenciales sobre cuál va a ser el desenlace del proceso se fijan en la instrucción. Ya en esta fase el inculpado tiene que poder defenderse, y por tanto se le tiene que proporcionar un defensor en el procedimiento de confrontación. La defensa en la instrucción debe ser fomentada, y no obstaculizada. El modelo de la "evidencia mediante del conflicto" (Evidence durch Widerstreit) debe tomarse en serio, lo que supone fortalecer el derecho a la inspección de los autos por parte de la defensa en la instrucción, es decir, debe exigirse un derecho formalizado a la defensa en la instrucción. Si la defensa puede de este modo personarse cuanto antes -y si uno confía en las conclusiones del DAV*-Forum que con el título “¿Proceso abreviado - procedimiento más largo?”, se celebraron en diciembre de $1996^{18}$, y yo no tengo motivos para dudar de ellas- se está eliminando una de las causas más importantes del alargamiento del juicio oral.

En los procedimientos de cooperación lo que se intenta es, con una comunicación abierta, ponerse de acuerdo sobre cuáles han de ser las consecuencias jurídicas constructivas en términos sociales que se derivan del delito que el inculpado ha reconocido. Una consecuencia jurídica social-constructiva es la reparación (Wiedergutmachung), quizás también la disculpa puede ser suficiente, o puede hablarse también de un perdón judicial en caso de reconocimiento de hechos por el acusado. Sin embargo, estas posibilidades no deben confundirse con el actual pacto. El procedimiento de cooperación es un proceso que requiere tiempo, pues busca la solución de un conflicto social, porque la conciliación supone que debe dejarse hablar a los participantes, y porque el efecto de satisfacción en la sociedad por este tipo de procedimientos sólo se produce cuando es evidente que los participantes se han esforzado.

“QQuo vadis, proceso penal?”. La respuesta es: por diferentes caminos hacia el objeto del proceso penal, es decir restablecer la paz jurídica, mediante la discusión abierta y correcta, cuando un acusado y su defensa quieren combatir; mediante un trabajo en común en la conciliación y en las consecuencias jurídicas social-constructivas, cuando un acusado reconoce su responsabilidad por una transgresión del Derecho y está dispuesto a una reparación. Pero, por favor no con ideologías irreflexivas o directivas ético-sociales en el equipaje.

Deutscher Anwaltsverein (DAV) Asociación Alemana de Abogados (N. del T.). Cft. con las aportaciones al Forum en Anw B1, 1997, pp. 73 y ss. 